\title{
Residue on Palate
}

National Cancer Institute

\section{Source}

National Cancer Institute. Residue on Palate. NCI Thesaurus. Code C127216.

A finding of oral residue remaining on palate after an individual swallows. 